\title{
Evaluation of the Visible and Shortwave Infrared Drought Index in China
}

\author{
Ning Zhang ${ }^{1,2}$, Yang Hong ${ }^{2}$, Qiming Qin ${ }^{1, *}$, and Lin $\mathrm{Zhu}^{3}$ \\ ${ }^{1}$ Institute of Remote Sensing and GIS, Peking University, Beijing 100871, China \\ ${ }^{2}$ School of Civil Engineering and Environmental Sciences, University of Oklahoma, OK 73072, USA \\ ${ }^{3}$ National Satellite Meteorological Center of China Meteorological Administration, Beijing 100081, China
}

\begin{abstract}
In this article, the performance of the Visible and Shortwave infrared Drought Index (VSDI), a drought index recently developed and validated in Oklahoma, United States, is further explored and validated in China. The in-situ measured soil moisture from 585 weather stations across China are used as ground-truth data, and five commonly used drought indices are compared with VSDI for surface drought monitoring. The results reveal that VSDI is robust and reliable in the estimation of surface dryness - it has the highest correlation with soil moisture among the six indices when computed using both the original and cloud removed data. All six indices show the highest correlation with soil moisture at the $10 \mathrm{~cm}$ layer and the averaged $10-50 \mathrm{~cm}$ layer. The spatiotemporal patterns of surface moisture indicated by the MODIS-based VSDI are further compared with the precipitation-based drought maps and the Global Land Data Assimilation System (GLDAS) simulated surface soil moisture maps over five provinces located in the Middle-Lower Yangtze Plain of China. The results indicate that despite the difference between the spatial and temporal resolutions of the three products, the VSDI maps still show good agreement with the other two drought products through the rapidly alternating drought and flood events in 2011 in this region. Therefore, VSDI can be used as an effective surface wetness indicator at both the provincial and the national scales in China.
\end{abstract}

Keywords China, drought map, drought monitoring, optical remote sensing, soil moisture, VSDI

\section{Introduction}

Drought is a slow developing phenomenon that accumulates over a period across a vast area, and its effects may last for years after it ends (Tannehill 1947). Droughts impact both surface and groundwater resources and can lead to reduced water supply, deteriorated water quality, crop failure, reduced range productivity, diminished power generation, and great economic and social damages (Riebsame, Changnon, and Karl 1991; Wilhite 2000; Mishra and Singh 2010). Bryant

\footnotetext{
* Corresponding author. E-mail: qmqinpku@163.com
}

(1991) ranked natural hazards based on various key characteristics including severity, duration, areal extent, loss of life, economic loss, social effect, long-term impact and so on, and found that drought ranks first among all natural hazards (Mishra and Singh 2010). Monitoring drought conditions and surface moisture status using satellite remote sensing is of great interest for drought disaster management and for the sustainable development of eco-environments.

In optical remote sensing, various studies have been conducted to investigate the effectiveness of existing drought indices in surface moisture monitoring. The Normalized Difference Vegetation Index (NDVI) is commonly used in vegetation drought monitoring (Brown et al. 2008). Jimmy and Andrew (2002) analyzed the sensitivity of NDVI to soil moisture in the U.S. Corn Belt and found weak correlation between them. Specifically, NDVI was found to lag 8 weeks behind the soil moisture variation. The research of Chen, Huang, and Jackson (2005) revealed that NDVI and the Normalized Difference Water Index (NDWI) were both good candidates for vegetation moisture monitoring, and NDWI performed better than NDVI, which is consistent with the findings of Jackson et al. (2004). Gu et al. (2007) also compared NDVI and NDWI using MODIS data for grassland drought assessment in the central United States. The results indicate strong relationships among NDVI, NDWI, and drought conditions, and NDWI had a quicker response to drought conditions than NDVI. However, the experiment conducted in Oklahoma, United States (Gu et al. 2008) indicated that NDVI and NDWI had comparable sensitivities to soil moisture variation and no additional benefit was gained by using NDWI. Yilmaz, Hunt, and Jackson (2008) analyzed the relationship between the Normalized Difference Infrared Index (NDII) (Hardinsky, Lemas, and Smart 1983) and Vegetation Water Content (VWC) through the Soil Moisture Experiment 2002 and 2005 (SMEX02 and SMEX05) in Iowa, United States, and concluded that NDII was related to canopy Equivalent Water Thickness (EWT) and indirectly related to VWC. Zhao et al. (2009) validated the shortwave infrared water stress index (SIWSI) developed by Fensholt and Sandholt (2003) in northwestern China and recommended 
using MODIS band 6 as shortwave infrared band in SIWSI calculation. Wang and Qu (2009) comprehensively reviewed progress in soil moisture monitoring using optical, thermal, passive microwave, and active microwave remote sensing techniques. Zhang et al. (2010) also reviewed advances in research of vegetation water content retrieval using optical remote sensing, including various vegetation moisture indices and the radiative transfer model (RTM) methods.

Recently, a simple method for the estimation of surface dryness, the Visible and Shortwave infrared Drought Index (VSDI), has been developed (Zhang et al. 2013). The VSDI is based on the combination of optical spectral bands located in Blue, Red, and Shortwave infrared (SWIR) regions. It shows potential advantages for monitoring both soil and vegetation moisture and for drought monitoring throughout plant growing seasons, which distinguish it from other drought indices that were either designed for vegetation water content estimation or confined to soil moisture monitoring. This index has been proven effective in monitoring the drought development over Oklahoma in the United States (Zhang et al. 2013), but its responses to moisture dynamics in other regions and different phenological conditions requires further examination.

The main objective of this study is to further explore the performance of VSDI in China as a surface drought index at the regional and national scales. To achieve this goal, two experiments were carried out: one to compare VSDI with five commonly used drought indices over China's 585 weather stations; and the other to compare VSDI drought maps with other drought products covering the Middle-Lower Yangtze Plain in China. Based on the above validation, VSDI can be deemed an efficient drought index applicable for drought monitoring in China at different scales. Our work on VSDI is to provide a new solution for future surface dryness monitoring and VSDI is expected to be used as a generalized drought index in various areas and ecosystems.

\section{Methods}

Five typical drought indices were selected as the candidate drought indices to compare with VSDI, including the Land Surface Water Index (LSWI) (Xiao et al. 2004), the Moisture Stress Index (MSI) (Hunt and Rock 1989), the Surface Water Capacity Index (SWCI) (Du et al. 2007), the Shortwave Infrared Soil Moisture Index (SIMI) (Yao et al. 2011), and the Normalized Difference Vegetation Index (NDVI) (Deering 1978). These indices are commonly used for surface dryness monitoring and only require optical spectral bands for calculation.

\subsection{Land Surface Water Index (LSWI)}

The LSWI is a popular drought index for vegetation moisture monitoring by using the normalized difference between Near-infrared (NIR) and shortwave infrared (SWIR) bands. It was proposed by Xiao et al. (2004) based on the band 2
(NIR, 841-876 nm) and band 6 (SWIR, 1628-1652 nm) of MODIS data:

$$
\mathrm{LSWI}=\left(\mathrm{R}_{\mathrm{NIR}}-\mathrm{R}_{\mathrm{SWIR}}\right) /\left(\mathrm{R}_{\mathrm{NIR}}+\mathrm{R}_{\mathrm{SWIR}}\right)
$$

This index has also been studied and referred to under other names, such as NDII (Hardinsky, Lemas, and Smart 1983), NDWI (Gao 1996), and SIWSI (Fensholt and Sandholt 2003), which varies with the specific wavelengths or sensordependent bands used. Despite the different names, one thing these indices have in common is that the NIR spectral region serves as a moisture reference band and the SWIR spectral domain is used as the moisture measuring band. This index has been proven effective in monitoring vegetation water content in a variety of studies (Zarco-Tejada, Rueda, and Ustin 2003; Maki, Ishiahra, and Tamura 2004; Xiao et al. 2005; Gu et al. 2008).

\subsection{Moisture Stress Index (MSI)}

The MSI is a simple water ratio index for the estimation of leaf relative water content (\%) and equivalent water thickness (EWT, $\mathrm{g} \mathrm{cm}^{-2}$ ) of different plant species (Hunt and Rock 1989). It is calculated as $R 1600 \mathrm{~nm} / \mathrm{R} 820 \mathrm{~nm}$. In this study, the SWIR band (band 6 of MODIS data) is used instead of the MIR band in equation 2 considering that the strong water absorption bands at SWIR spectrum are more sensitive to moisture variation than other optical spectral regions (Dawson et al. 1999; Ceccato et al. 2001; Chuvieco et al. 2002). In addition, the weak water absorption at NIR band makes it less sensitive to water variation (Gao 1996; Ghulam et al. 2008), thus the ratio between SWIR and NIR bands can effectively reduce the scattering effect of the single band and highlight the water variation in vegetation leaves.

$$
\mathrm{MSI}=\mathrm{R}_{\mathrm{SWIR} \sigma} / \mathrm{R}_{\mathrm{NIR}}
$$

Eq. 2

\subsection{Surface Water Capacity Index (SWCI)}

The SWCI is a surface moisture index constructed by using the normalized difference between two SWIR bands (bands 6 and 7) of MODIS data (Du et al. 2007):

$$
\mathrm{SWCI}=\left(\mathrm{R}_{\text {SWIR } 6}-\mathrm{R}_{\text {SWIR7 }}\right) /\left(\mathrm{R}_{\text {SWIR6 }}+\mathrm{R}_{\text {SWIR7 }}\right) \quad \text { Eq. } 3
$$

Since MODIS band $6(1628-1652 \mathrm{~nm})$ and band 7 (2105$2155 \mathrm{~nm}$ ) correspond to the valley and the peak of the water absorption curve respectively and are both sensitive to moisture variation, the difference between the two bands $\left(\mathrm{R}_{\text {SWIR } 6}-\mathrm{R}_{\text {SWIR } 7}\right)$ has the potential of indicating the surface dryness conditions and reducing the atmospheric effect to some extent considering the similar response of the two bands to atmospheric influences. The term $\mathrm{R}_{\text {SWIR } 6}+\mathrm{R}_{\text {SWIR } 7}$ is used to limit the index value within -1 and 1 . The validation results indicate that SWCI has strong correlation with soil water content in Inner Mongolia and Liaoning Province of China (Du et al. 2007). Compared with NDVI, SWCI also presents higher correlation with the average soil moisture for the 0-50 cm layer in Henan Province of China (Zhang et al. 2008). 


\subsection{Shortwave Infrared Soil Moisture Index (SIMI)}

The SIMI (Yao et al. 2011) is a soil moisture index developed based on the SWIR spectral space using MODIS band 6 and band 7 data. It can also be applied to remote sensor with two shortwave infrared bands centered on $1650 \mathrm{~nm}$ and $1950 \mathrm{~nm}$.

$$
\mathrm{SIMI}=\sqrt{\left(\mathrm{R}_{\text {SWIR6 }}^{2}+\mathrm{R}_{\text {SWIR } 7}{ }^{2}\right) / 2}
$$

The combined use of MODIS band 6 and band 7 in the SWIR spectral space can highlight the moisture information and reduce the disturbance from the complex land surface components at the same time. This index has been proven more efficient than the Temperature-Vegetation index (TVX), which is the ratio between Land Surface Temperature (LST) and NDVI, in soil moisture retrieval in Ningxia Hui Autonomous Region of China (Yao et al. 2011).

\subsection{Normalized Difference Vegetation Index (NDVI)}

$$
\mathrm{NDVI}=\left(\mathrm{R}_{\mathrm{NIR}}-\mathrm{R}_{\mathrm{RED}}\right) /\left(\mathrm{R}_{\mathrm{NIR}}+\mathrm{R}_{\mathrm{RED}}\right) \quad \text { Eq. } 5
$$

The NDVI is a well-known vegetation greenness index based on the normalized difference between NIR and Red reflectance. It has been widely applied in drought monitoring under the assumption that water stress is the most important factor that interferes with the plant growing process (McVicar and Bierwirth 2001; Ji and Peters 2003; Wan, Wang, and Li 2004; Wang et al. 2007; Gu et al. 2007, 2008; Brown et al. 2008).

\subsection{Visible and Shortwave infrared Drought Index (VSDI)}

The VSDI is a newly developed drought index for drought monitoring of both soil and vegetation surfaces. This index is a combination of MODIS Blue (band 3), Red (band 1), and SWIR (band 6) bands, and is defined in equation 6:

$$
\text { VSDI }=1-\left[\left(\mathrm{R}_{\text {SwIR6 }}-\mathrm{R}_{\text {Blue }}\right)+\left(\mathrm{R}_{\text {Red }}-\mathrm{R}_{\text {Blue }}\right)\right]
$$

By analyzing the spectral response to water stress of plants and soils, SWIR and Red bands are found sensitive to moisture variation for both types of surfaces, thus they are used as the moisture measuring bands. The Blue band is less sensitive to water changes and can serve as the moisture benchmark (Zhang et al. 2013). In this way, VSDI is constructed based on the difference between moisture sensitive bands (SWIR and Red) and reference band (Blue). The combination of $\left(\mathrm{R}_{\text {SWIR }}-\mathrm{R}_{\text {Blue }}\right)$ and $\left(\mathrm{R}_{\mathrm{Red}}-\mathrm{R}_{\text {Blue }}\right)$ may maximize the moisture variation and give the potential to estimate surface water independent of land cover types. Finally, " $\left(\mathrm{R}_{\text {SWIR }}-\mathrm{R}_{\text {Blue }}\right)+$ $\left(\mathrm{R}_{\mathrm{Red}}-\mathrm{R}_{\text {Blue }}\right)$ " is subtracted from 1 to make VSDI positively correlated to moisture variation. The theoretical VSDI range is defined in Table 1 with brief explanation.

The validation of VSDI was carried out in Oklahoma, United States using the soil moisture measurements from 49 Mesonet stations. ${ }^{i}$ The results show that VSDI presented high correlation with soil moisture and was efficient for drought monitoring over different land cover types and was applicable throughout the plant growing seasons in Oklahoma (Zhang et al. 2013).

\section{Test Site and Data Processing}

Our study area is located in China (Figure 1) and the evaluation of the performance of VSDI was conducted at two scales. First, the soil moisture measurements from 585 meteorological and environmental observation stations across China (indicated by black dots in Figure 1) were used as groundtruth data to compare VSDI with other drought indices. At these stations soil moisture is measured for every 10 days and recorded as relative soil moisture at three depths $-10 \mathrm{~cm}$, $20 \mathrm{~cm}$, and $50 \mathrm{~cm}$. The mean $10-20 \mathrm{~cm}$ soil moisture (later referred to as 20 ave) and the mean $10-50 \mathrm{~cm}$ moisture (later referred to as 50 ave) were also calculated respectively by average soil moisture of the first two layers and all three layers. The data for the 585 stations used in this research are from March to October in 2011.

Second, VSDI is investigated at a smaller scale in the Middle-Lower Yangtze Plain in southeast China (the enlarged area in Figure 1). Five provinces are included in this region: Hubei, Hunan, Auhui, Jiangxi, and Zhejiang Provinces. In 2011, this region experienced frequent severe drought and flood events; thus it represents an interesting case for examining the performance of VSDI under extreme weather conditions.

For the Yangtze River region, the monthly precipitation anomaly data were collected from 84 local weather stations (denoted by the plus signs in Figure 1). The station-based precipitation anomalies are interpolated using Kriging interpolation (Oliver 1990) embedded in ArcGIS software to produce a continuous precipitation map. With reference to the four precipitation anomaly-based drought categories (indicated by asterisks in Table 2) defined in the Chinese Classification of Meteorological Drought (GB/T 20481-2006) (China Meteorological Administration 2006), five more categories were introduced and finally nine drought categories were adopted to describe the moisture condition of this region (Table 2).

The remote sensing data used in this study are the 8-day MODIS reflectance products (MOD09A1). The spatial resolution of MOD09A1 is $500 \mathrm{~m}$ for bands $1-7$ covering the

Table 1. Definition of the theoretical range of the Visible and Shortwave Infrared Drought Index (VSDI)

\begin{tabular}{ll}
\hline $0<$ VSDI $\leq 1$ & $\begin{array}{l}\text { The smaller the value is, the drier the condition it } \\
\text { indicates (for the surface of farmland or any surface that } \\
\text { can be simply classified as soil, vegetation and the } \\
\text { combination of the two) }\end{array}$ \\
$1<$ VSDI $\leq 2$ & $\begin{array}{l}\text { Water or Snow Water Equivalent (including water bodies, } \\
\text { snow, and ice cover) }\end{array}$
\end{tabular}

Source: Zhang et al. (2013) 


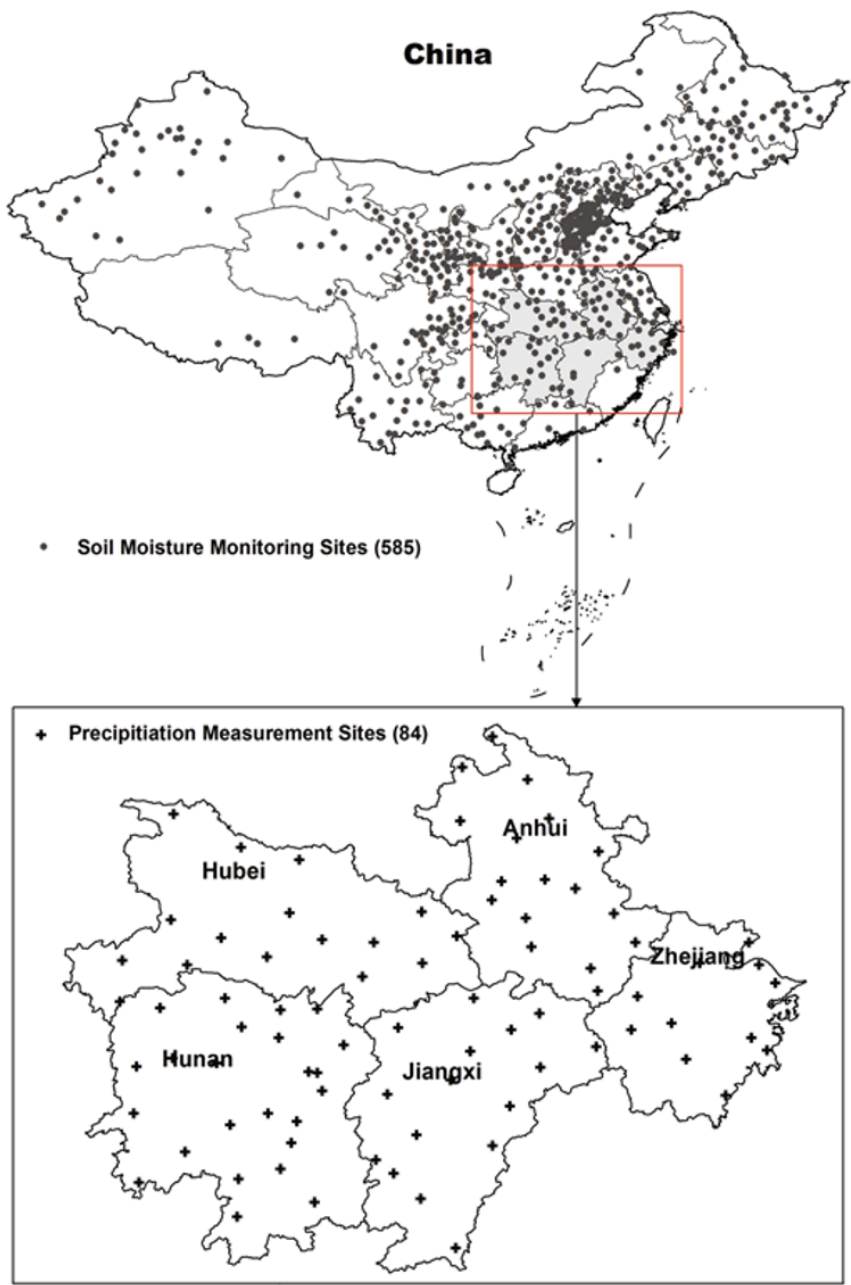

Figure 1. Map of the study area in China. The black dots (upper panel) represent the $\mathbf{5 8 5}$ weather stations across China where the relative soil moisture data were obtained. The plus signs (lower panel) denote the $\mathbf{8 4}$ weather stations within the five provinces in the Middle-Lower Yangtze Plain where precipitation anomalies were recorded

visible, near-infrared, and shortwave-infrared spectral domains. The MODIS data were obtained from two sources. In accordance with the station-based soil moisture measurements, the MODIS reflectance data that geographically correspond to the 585 weather stations were downloaded

Table 2. Drought categories based on precipitation anomalies $\left(P_{\mathrm{a}}\right)$. The asterisks indicate the drought categories defined in the Chinese Classification of Meteorological Drought (GB/T 20481-2006) (China Meteorological Administration 2006)

\begin{tabular}{llll}
\hline Moisture Condition & $\boldsymbol{P}_{\mathrm{a}}$ Range & Moisture Condition & $\boldsymbol{P}_{\mathrm{a}}$ Range \\
\hline Normal & $-40<P_{\mathrm{a}} \leq 40$ & Abnormally wet & $40<P_{\mathrm{a}} \leq 60$ \\
Abnormally dry* $^{*}$ & $-60<P_{\mathrm{a}} \leq-40^{*}$ & Moderately wet & $60<P_{\mathrm{a}} \leq 80$ \\
Moderate drought* $^{*}$ & $-80<P_{\mathrm{a}} \leq-60^{*}$ & Severely wet & $80<P_{\mathrm{a}} \leq 95$ \\
Severe drought $^{*}$ & $-95<P_{\mathrm{a}} \leq-80^{*}$ & Extremely wet & $95<P_{\mathrm{a}}$ \\
Extreme drought $^{*}$ & $P_{\mathrm{a}} \leq-95^{*}$ & & \\
\hline
\end{tabular}

from the Earth Observation and Modeling website of the University of Oklahoma (http://www.eomf.ou.edu/), which provides the retrieved time series MODIS data for multiple sites. Considering the different time intervals between MODIS data (8-day period) and the soil moisture measurements (10-day period), the MODIS images that have the longest overlap with the 10-day ground-truth data were selected for correlation analysis. Considering that cloud contamination is a major problem in optical remote sensing application, the reflectance data before and after the quality control and exclusion of cloud contaminated pixels are both used in this study for computing and comparing the six drought indices and to evaluate the cloud influences on these indices in large scale.

For the investigation of the alternating drought and flood events in the Middle-Lower Yangtze region, the MODIS images covering the five provinces were downloaded from NASA's LAADS Web (Level 1 and Atmosphere Archive and Distribution System, http://ladsweb.nascom.nasa.gov/data) and mosaicked. A quality control process was applied to filter the "cloud" pixels by using the MODIS quality assurance (QA) data product.

Another set of data used in this study comes from a web-based application developed by Goddard Earth Sciences Data and Information Services Center (GES DISC), called Giovanni. It provides a simple and intuitive way to visualize, analyze, and access vast amounts of earth science remote sensing data without having to download the data (http://disc. sci.gsfc.nasa.gov/giovanni/overview/). In this study, the monthly data set of average soil moisture at the $0-10 \mathrm{~cm}$ layer simulated by the GLDAS-1 NOAH Model were selected from the Global Land Data Assimilation System (GLDAS) data portal in Giovanni. This data set covers the period from January 1979 to May 2012 and has a spatial resolution of 1 degree. The modeled monthly soil moisture of the five provinces was produced by Giovanni and used for the following analysis.

\section{Results and Discussion}

Using the above data sets, VSDI was validated by comparing with the other five drought indices and drought maps. The results are discussed in this section.

\subsection{Comparison among Different Drought Indices}

In this study, the ground-truth data (relative soil moisture) are assumed to have a normal distribution. The Correlation Coefficient (R), which is a measure of the strength of linear dependence between two variables, is calculated between the six drought indices (VSDI, LSWI, MSI, SWCI, SIMI, and NDVI) and the relative soil moisture respectively. The Correlation Coefficient $\mathrm{R}$ is computed at five depths $(10 \mathrm{~cm}$, $20 \mathrm{~cm}, 50 \mathrm{~cm}, 20 \_$ave, and 50_ave) over 585 stations across China, and two atmospheric conditions are also consideredone represented by the original images and the other by 
Table 3. The Correlation Coefficient $(R)$ calculated between each of the six drought indices ${ }^{\dagger}$ and relative soil moisture at five depths from 585 weather stations across China. A maximum number of 17,550 samples (30 periods $x 585$ stations) are included in the statistical analysis. Fisher $(F)$ Test is conducted to test this linear regression and the $R s$ for all indices have passed the significance test $\left(p \_v a l u e<0.05\right)$. The original condition stands for the results without quality control (cloud pixels included in $\mathbf{R}$ computation) and the cloud removed condition denotes that the cloud pixels have been filtered before $\mathrm{R}$ calculation.

\begin{tabular}{|c|c|c|c|c|c|c|c|c|c|c|c|c|c|c|c|c|}
\hline \multirow[t]{3}{*}{ Condition } & \multirow[t]{3}{*}{ Indices } & \multicolumn{15}{|c|}{ Relative Soil Moisture } \\
\hline & & \multicolumn{3}{|c|}{$10 \mathrm{~cm}$} & \multicolumn{3}{|c|}{$20 \mathrm{~cm}$} & \multicolumn{3}{|c|}{$50 \mathrm{~cm}$} & \multicolumn{3}{|c|}{ 20_ave } & \multicolumn{3}{|c|}{ 50_ave } \\
\hline & & $\boldsymbol{R}$ & $F_{-}$value & $p_{-}$value & $R$ & $F_{-}$value & p_value & $\boldsymbol{R}$ & $F_{-}$value & $p_{-}$value & $R$ & $F_{-}$value & $p_{-}$value & $\boldsymbol{R}$ & $F_{-}$value & p_value \\
\hline \multirow[t]{6}{*}{ Original } & VSDI & 0.39 & 2142.8 & 0.00 & 0.37 & 1863.8 & 0.00 & 0.37 & 1794.2 & 0.00 & 0.39 & 2121.1 & 0.00 & 0.41 & 2358.1 & 0.00 \\
\hline & LSWI & 0.23 & 643.6 & 0.00 & 0.19 & 455.4 & 0.00 & 0.23 & 641.3 & 0.00 & 0.21 & 573.0 & 0.00 & 0.25 & 768.9 & 0.00 \\
\hline & MSI & -0.23 & 651.8 & 0.00 & -0.19 & 460.0 & 0.00 & -0.24 & 685.1 & 0.00 & -0.22 & 579.2 & 0.00 & -0.26 & 826.9 & 0.00 \\
\hline & SWCI & 0.27 & 923.2 & 0.00 & 0.23 & 690.1 & 0.00 & 0.26 & 840.9 & 0.00 & 0.26 & 851.1 & 0.00 & 0.29 & 1042.9 & 0.00 \\
\hline & SIMI & -0.24 & 747.5 & 0.00 & -0.23 & 691.9 & 0.00 & -0.26 & 859.0 & 0.00 & -0.24 & 755.5 & 0.00 & -0.26 & 842.9 & 0.00 \\
\hline & NDVI & 0.15 & 262.3 & 0.00 & 0.12 & 162.9 & 0.00 & 0.17 & 352.2 & 0.00 & 0.13 & 220.3 & 0.00 & 0.18 & 372.3 & 0.00 \\
\hline \multirow{6}{*}{$\begin{array}{l}\text { Cloud } \\
\text { removed }\end{array}$} & VSDI & 0.35 & 1474.6 & 0.00 & 0.34 & 1345.1 & 0.00 & 0.35 & 1411.5 & 0.00 & 0.35 & 1489.3 & 0.00 & 0.38 & 1742.4 & 0.00 \\
\hline & LSWI & 0.20 & 436.0 & 0.00 & 0.17 & 296.2 & 0.00 & 0.21 & 479.0 & 0.00 & 0.19 & 380.5 & 0.00 & 0.23 & 561.0 & 0.00 \\
\hline & MSI & -0.20 & 443.2 & 0.00 & -0.17 & 299.2 & 0.00 & -0.22 & 512.6 & 0.00 & -0.19 & 385.3 & 0.00 & -0.24 & 606.7 & 0.00 \\
\hline & SWCI & 0.26 & 783.9 & 0.00 & 0.23 & 576.3 & 0.00 & 0.25 & 699.1 & 0.00 & 0.25 & 717.7 & 0.00 & 0.28 & 869.9 & 0.00 \\
\hline & SIMI & -0.35 & 1473.7 & 0.00 & -0.33 & 1319.3 & 0.00 & -0.36 & 1516.3 & 0.00 & -0.35 & 1475.3 & 0.00 & -0.38 & 1704.6 & 0.00 \\
\hline & NDVI & 0.22 & 548.5 & 0.00 & 0.18 & 361.6 & 0.00 & 0.23 & 553.2 & 0.00 & 0.21 & 474.7 & 0.00 & 0.24 & 657.9 & 0.00 \\
\hline
\end{tabular}

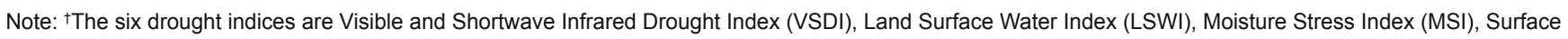
Water Capacity Index (SWCI), Shortwave Infrared Soil Moisture Index (SIMI), and Normalized Difference Vegetation Index (NDVI).

images with "cloudy" pixels removed. The results are listed in Table 3. Figure 2 shows the scatter plots and the linear fitting between the six drought indices and the $10 \mathrm{~cm}$ relative soil moisture. The cloud pixels have been eliminated from the analysis in Figure 2.

From Table 3 we can see that among the six indices, MSI and SIMI are negatively correlated to soil moisture variation, while other indices have positive correlation with surface dryness. The absolute value of correlation coefficients $(|R|)$ between the six drought indices and soil moisture at all depths ranges from 0.13 to 0.41 . It is worth explaining that although all $R$ values have passed the significance test, they are not significantly high. The coefficient of determination values $\left(R^{2}\right)$ of the six indices, which describes the proportion of variance in a data set that is accounted for by the statistical model (Steel and Torrie 1960), are relatively low with the highest
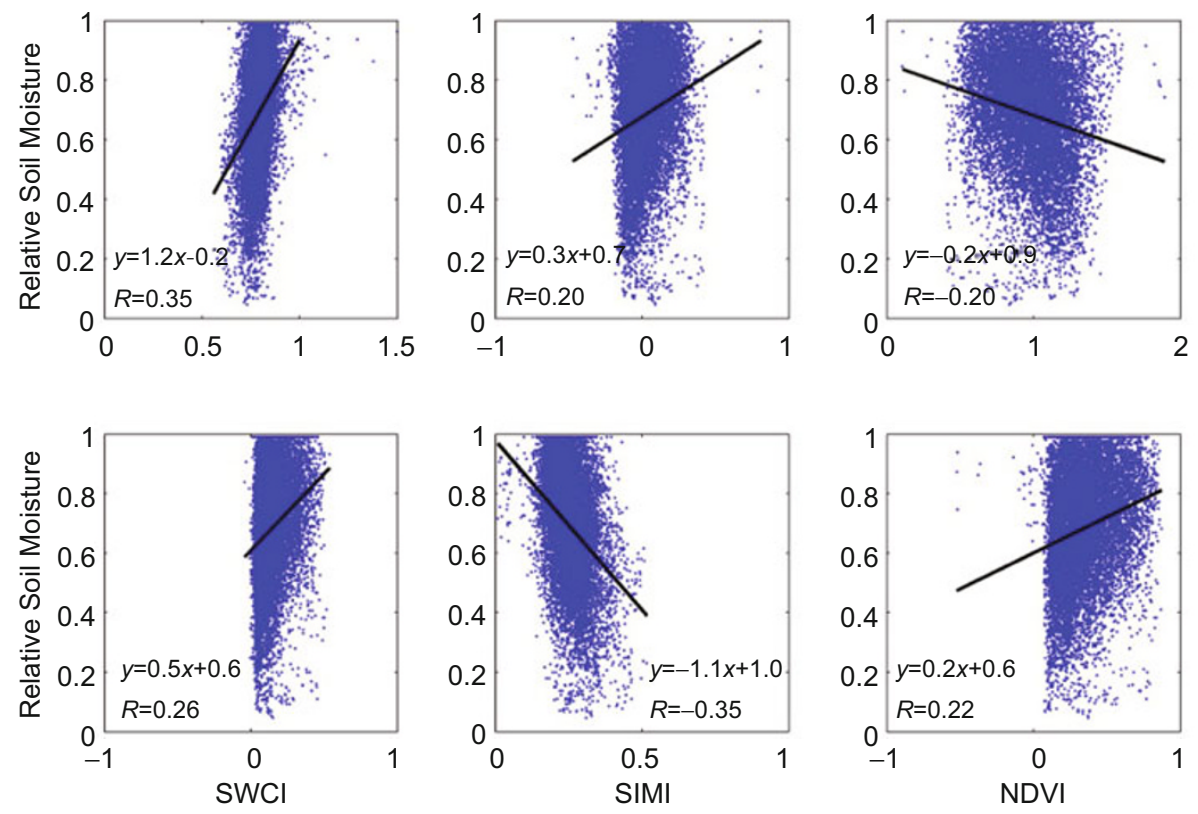

Figure 2. Scatter plots between each drought index (VSDI, LSWI, MSI, SWCI, SIMI, and NDVI) and the $10 \mathrm{~cm}$ relative soil moisture over 585 stations across China. The cloud contaminated pixels have been removed from this correlation analysis 
value of 0.17 found in VSDI. Several reasons may be ascribed to this phenomenon, such as the different spatial resolution between MODIS data $(500 \mathrm{~m})$ and the ground-truth data (station-based point measurements), the mismatch of the temporal resolution of the two data sets, and the positioning and image registration errors, which may all add great uncertainties to the final results and reduce the proportion of variance that may be explained by the indices themselves. However, given that all six drought indices are calculated and processed in the same way and may be affected by the same factors, and the five other indices are representative moisture indices and have been proved efficient in moisture estimation by a variety of studies, the correlation results can be considered reliable and the relative superior performance of VSDI (with higher $R$ values) compared with other indices can justify the capability of VSDI for moisture monitoring.

For both conditions (original and cloud removed), VSDI possesses the highest $\mathrm{R}$ values among the six indices, followed by the soil moisture drought indices (SWCI and SIM), which are slightly higher than that of the vegetation drought indices (LSWI and MSI). It is also worth noting that, after removing the cloud contaminated pixels (Table 3 and Figure 2), both SIMI and NDVI show enhanced correlation with the observed relative soil moisture: the performance of SIMI is almost as good as VSDI and NDVI has higher R values than the vegetation drought indices (LSWI and MSI). In contrast, other indices show slightly subdued correlation with the observed relative soil moisture after excluding the cloud contamination. The results suggest that VSDI is an efficient and reliable drought index among the six indices and the atmospheric conditions may have a stronger effect on SIMI and NDVI compared with other indices. In this sense, the cloud pixels should be removed or cloud-free conditions should be selected when applying SIMI and NDVI for surface moisture monitoring with high accuracy.

A further examination of Table 3 also reveals that for both conditions (original and cloud removed), all indices seem to have higher correlation with surface soil moisture $(10 \mathrm{~cm}$ layer) than soil moisture at deeper layers $(20 \mathrm{~cm}$ and $50 \mathrm{~cm})$. This can be explained by the limited penetrability of optical remote sensing signals. With the attenuation of optical signals, less information can be gathered from the deeper layers, and therefore a decreased correlation with soil moisture at these layers can be expected. Besides, stronger correlations are also observed between averaged soil moisture and drought indices, especially for the $10-50 \mathrm{~cm}$ layer. This may be due to the averaging effect that reduces the measuring noises by averaging soil moisture from different layers. Therefore, for operational applications the optical drought indices are recommended to estimate the surface dryness or the average soil moisture content.

\subsection{Comparison with Other Drought Maps}

In this study, the VSDI color maps for five provinces (Hubei, Hunan, Auhui, Jiangxi, and Zhejiang) in the Middle-Lower Yangtze Plain (Figure 1) were also produced and compared with two other drought products: the monthly drought classification maps based on precipitation anomalies; and the monthly average soil moisture in the $0-10 \mathrm{~cm}$ layer simulated by the GLDAS-1 NOAH Model from Giovanni (http://disc. sci.gsfc.nasa.gov/giovanni/overview/index.html). The acquisition and processing of the two drought products were introduced in Section 3. Finally, the three drought products are plotted and compared in Figure 3. The first column shows the precipitation-based drought maps with 9 moisture categories (as listed in Table 2). The middle column shows the GLDAS simulated monthly surface soil moisture. The last column shows the VSDI color maps calculated from the 8 -day MODIS reflectance products. Considering the difference in temporal resolution between the first two products (monthly) and VSDI color maps (8-day), the cloud-free VSDI images covering the middle or the last period of each month are selected for comparison.

From Figure 3, both agreement and some differences can be observed among the three products. In April, all drought maps indicate serious water-stressed conditions with warm and red color in the northern and southern parts of the study area, especially in Anhui and Jiangxi Provinces. This is consistent with the drought events that started early in 2011 and were still persistent at this time in this area. In May, the drought condition seems relieved to some extent in the south of the study area (Hunan and Jiangxi Provinces) with light and blue color presented in all three products. However, for the northern part, both the soil moisture product and the VSDI product indicate sustained water stress, while the precipitation-based drought map shows a normal to abnormally dry condition. In June, the first two products show an apparent moderate to severe wet condition (blue color) in the middle of the study area along the Yangtze River. This is consistent with the flood events that struck this area from early June. Since the cloud pixels have been filtered from the VSDI maps, the middle part of the VSDI color map on June 10 is almost blank, which means that heavy cloud was persistent in this area. This can be viewed as an indirect indication of the flood events considering that heavy rains usually coincide with heavy clouds. In July, drought conditions can be observed from all three products in the western and northern parts of the study area, but relatively wet conditions can be observed in the last two products in the eastern and southern parts. In August, a wet condition can be observed in the northeastern part of the study area in the first two products and corresponds to the blank area in the VSDI map after removing the cloud contamination. In August the drought condition in the VSDI map is more prominent in the southwestern part than in the other two products.

In summary, there are satisfactory agreements among the three products, especially between the GLDAS modeled surface soil moisture and the VSDI maps. This is reasonable because for these two products drought is measured by surface soil moisture, but for the precipitation maps drought is measured by precipitation anomalies. The different temporal resolution (monthly vs. 8-day) may also have contributed to 

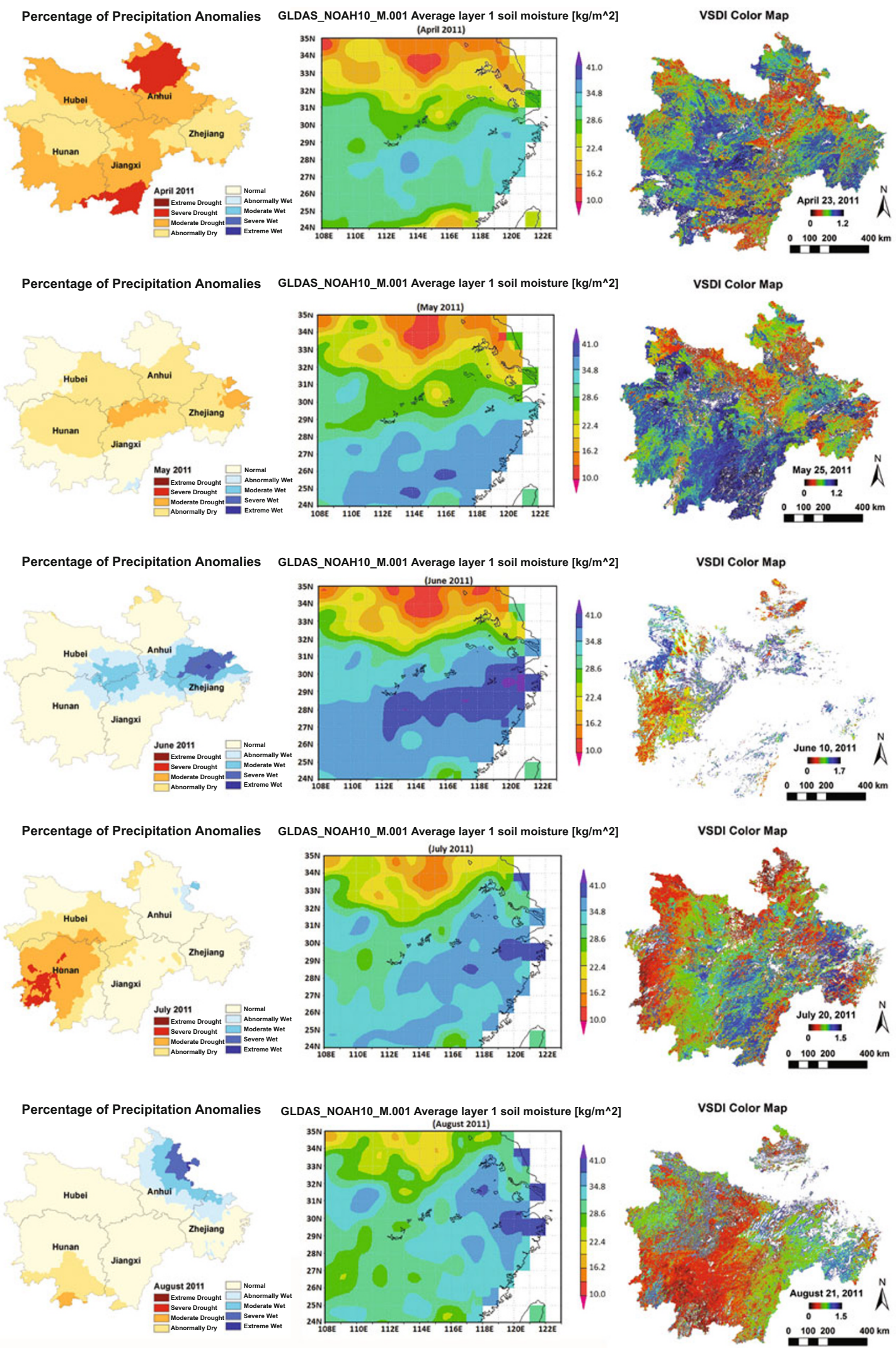

Figure 3. Comparison between different drought maps of the five provinces located in the Middle-Lower Yangtze Plain from April to August, 2011. The first column shows the drought maps produced by interpolating the monthly precipitation anomalies from the 84 weather stations. The middle column shows the GLDAS modeled monthly surface soil moisture (10 cm) from a web-based visualization application, Giovanni (http://disc.sci.gsfc.nasa.gov/giovanni/overview/index.html). The last column shows the VSDI color maps calculated from the 8-day MODIS reflectance products 
the differences among the three products. In general, VSDI can be viewed as an effective tool for monitoring surface moisture conditions. Compared with the precipitation-based drought maps interpolated from the 84 weather stations and the 1-degree GLDAS simulated soil moisture maps, the VSDI maps have a spatial resolution of $500 \mathrm{~m}$, which may facilitate a finer-scale interpretation of surface moisture distribution. Although not elaborated in this study, the relatively high temporal resolution of VSDI maps (8-day) may also enable a closer and timely monitoring of drought development.

\section{Conclusion}

In this article, VSDI, a drought index recently developed, is further explored and validated in China. We come to the following conclusions:

The six optical drought indices applied in this study all have the ability of monitoring surface dryness and higher correlation is observed both with the top $10 \mathrm{~cm}$ layer and the $10-50 \mathrm{~cm}$ averaged soil moisture than with the single deeper layer (that is, $20 \mathrm{~cm}$ and $50 \mathrm{~cm}$ ) and the $10-20 \mathrm{~cm}$ averaged moisture. Therefore, it is suggested that the optical drought indices can be used to better monitor the surface soil moisture $(10 \mathrm{~cm})$ or multilayer averaged soil moisture than in other cases.

Among the six drought indices, VSDI shows the highest correlation with soil moisture at various depths using both the original and cloud removed data. SIMI has similar performance as VSDI after removing the cloud pixels, and both SIMI and NDVI show enhanced correlation, while the correlations of other indices are slightly decreased after removing the cloud contamination. This suggests that VSDI is robust and reliable in the estimation of surface dryness among the six indices. SIMI and NDVI are more sensitive to atmospheric influences compared with other indices, therefore either images under clear weather conditions should be selected or atmospheric correction should be conducted before applying these two indices for drought monitoring.

Although differences exist among the three drought products for the Yangtze River region due to the different spatial and temporal resolutions, VSDI maps show a satisfactory agreement with the other two moisture products, even in the case of alternating drought and flood events in the study area. The MODIS-based VSDI maps have higher temporal and spatial resolutions than the other two products, and therefore may serve as an effective tool in real-time regional surface drought monitoring at field scale.

\section{Acknowledgments}

The authors would like to thank the National Satellite Meteorological Center of China Meteorological Administration for providing the ground measurement data. The authors also thank Dr. Zhenghong Tang, Dr. Jianjun $\mathrm{Wu}$, and the anonymous reviewers for their critical and helpful comments and suggestions. The authors appreciate the kind financial support of the National Natural Science Foundation of China (41230747, 41071221, 41201331) and the National Key Technology R\&D Program in the 12th Five-Year Plan of China (2012BAH29B03). The first author also likes to thank the HyDROS Lab (http://hydro.ou.edu) at the National Weather Center, Norman, Oklahoma, United States, for the helpful and valuable suggestions for this article.

\section{Note}

i The Mesonet stations are an extensive environmental observation network located in Oklahoma, United States, which can provide quality-controlled measurements of meteorological and land surface parameters such as precipitation, temperature, and soil moisture every five minutes. More detailed information can be found at http:// www.mesonet.org/.

\section{References}

Brown, J. F., B. D. Wardlow, T. Tadesse, M. J. Hayes, and B. C. Reed. 2008. The Vegetation Drought Response Index (VegDRI): A New Integrated Approach for Monitoring Drought Stress in Vegetation. GIScience and Remote Sensing 45 (1): 16-46.

Bryant, E. A. 1991. Natural Hazards. Cambridge, UK: Cambridge University Press.

Ceccato, P., S. Flasse, S. Tarantola, S. Jacquemoud, and J. Gregoire. 2001. Detecting Vegetation Leaf Water Content Using Reflectance in the Optical Domain. Remote Sensing of Environment 77 (1): 22-33.

Chen, D., J. Huang, and T. J. Jackson. 2005. Vegetation Water Content Estimation for Corn and Soybeans Using Spectral Indices Derived from MODIS Near- and Short-Wave Infrared Bands. Remote Sensing of Environment 98 (2-3): 225-236.

China Meteorological Administration. 2006. Chinese Classification of Meteorological Drought. GB/T 20481-2006. http://www.tsinfo.js.cn/ inquiry/gbtdetails.aspx?A100=GB/T\%2020481-2006.

Chuvieco, E., D. Riãno, I. Aguado, and D. Cocero. 2002. Estimation of Fuel Moisture Content from Multitemporal Analysis of Landsat Thematic Mapper Reflectance Data: Applications in Fire Danger Assessment. International Journal of Remote Sensing 23 (11): 21452162.

Dawson, T. P., P. J. Curran, P. R. J. North, and S. E. Plummer. 1999. The Propagation of Foliar Biochemical Absorption Features in Forest Canopy Reflectance: A Theoretical Analysis. Remote Sensing of Environment 67 (2): 147-159.

Deering, D. W. 1978. Rangeland Reflectance Characteristics Measured by Aircraft and Spacecraft Sensors. Ph.D. Dissertation, Texas A \& M University, College Station, TX.

Du, X., S. Wang, Y. Zhou, and H. Wei. 2007. Construction and Validation of a New Model for Unified Surface Water Capacity Based on MODIS Data. Geomatics and Information Science of Wuhan University 32 (3): 205-207 (in Chinese).

Fensholt, R., and I. Sandholt. 2003. Derivation of a Shortwave Infrared Stress Index from MODIS Near- and Shortwave Infrared Data in a Semiarid Environment. Remote Sensing of Environment 87 (1): $111-121$

Gao, B. C. 1996. NDWI-A Normalized Difference Water Index for Remote Sensing of Vegetation Liquid Water from Space. Remote Sensing of Environment 58 (3): 257-266. 
Ghulam, A., Z. L. Li, Q. M. Qin, H. Yimit, and J. H. Wang. 2008. Estimating Crop Water Stress with ETM+NIR and SWIR Data. Agricultural and Forest Meteorology 148 (11): 1679-1695.

Gu, Y., J. F. Brown, J. P. Verdin, and B. Wardlow. 2007. A Five-Year Analysis of MODIS NDVI and NDWI for Grassland Drought Assessment Over the Central Great Plains of the United States. Geophysical Research Letters 34 (6): L06407.

Gu, Y., E. Hunt, B. Wardlow, J. B. Basara, J. F. Brown, and J. P. Verdin. 2008. Evaluation of MODIS NDVI and NDWI for Vegetation Drought Monitoring Using Oklahoma Mesonet Soil Moisture Data. Geophysical Research Letters 35 (5): L22401.

Hardinsky, M. A., V. Lemas, and R. M. Smart. 1983. The Influence of Soil Salinity, Growth Form, and Leaf Moisture on the Spectral Reflectance of Spartina Alternifolia Canopies. Photogrammetric Engineering and Remote Sensing 49 (1): 77-83.

Hunt, Jr. E. R., and B. N. Rock. 1989. Detection of Changes in Leaf Water Content Using Near- and Middle-Infrared Reflectance. Remote Sensing of Environment 30 (1): 43- 54.

Jackson, T. J., D. Chen, M. Cosh, F. Li, M. Anderson, C. Walthall, P. Doriaswamy, and E. R. Hunt. 2004. Vegetation Water Content Mapping Using Landsat Data Derived Normalized Difference Water Index for Corn and Soybeans. Remote Sensing of Environment 92 (4): 475-482.

Ji, L., and A. J. Peters. 2003. Assessing Vegetation Response to Drought in the Northern Great Plains Using Vegetation and Drought Indices. Remote Sensing of Environment 87 (1): 85-98.

Jimmy, O. A., and M. C. Andrew. 2002. Relations between Soil Moisture and Satellite Vegetation Indices in the U.S. Corn Belt. Journal of Hydrometeorology 3 (4): 395-405.

Maki, M., M. Ishiahra, and M. Tamura. 2004. Estimation of Leaf Water Status to Monitor the Risk of Forest Fires by Using Remotely Sensed Imagery. Remote Sensing of Environment 90 (4): 441-450.

McVicar, T. R., and P. N. Bierwirth. 2001. Rapidly Assessing the 1997 Drought in Papua New Guinea Using Composite AVHRR Imagery. International Journal of Remote Sensing 22 (11): 2109-2128.

Mishra, A. K., and V. P. Singh. 2010. A Review of Drought Concepts. Journal of Hydrology 391 (1-2): 202-216.

Oliver, M. A. 1990. Kriging: A Method of Interpolation for Geographical Information Systems. International Journal of Geographic Information Systems 4 (3): 313-332.

Riebsame, W. E., S. A. Changnon, and T. R. Karl. 1991. Drought and Natural Resource Management in the United States: Impacts and Implications of the 1987-1989 Drought. Boulder, CO: Westview Press.

Steel, R. G. D., and J. H. Torrie. 1960. Principles and Procedures of Statistics. New York: McGraw-Hill.

Tannehill, I. R. 1947. Drought: Its Causes and Effects. Princeton, NJ: Princeton University Press.
Wan, Z., P. Wang, and X. Li. 2004. Using MODIS Land Surface Temperature and Normalized Difference Vegetation Index for Monitoring Drought in the Southern Great Plains, USA. International Journal of Remote Sensing 25 (1): 61-72.

Wang, L., and J. J. Qu. 2009. Satellite Remote Sensing Applications for Surface Soil Moisture Monitoring: A Review. Frontiers of Earth Science in China 3 (2): 237-247.

Wang, X., H. Xie, H. Guan, and X. Zhou. 2007. Different Responses of MODIS-Derived NDVI to Root-Zone Soil Moisture in Semi-Arid and Humid Regions. Journal of Hydrology 340 (1 -2): 12-24.

Wilhite, D. A. 2000. Drought as a Natural Hazard: Concepts and Definitions. In Drought: A Global Assessment, Vol. I, edited by D. A. Wilhite, 3-18. New York: Routledge.

Xiao, X., S. Boles, J. Liu, D. Zhuang, S. Frolking, C. Li, W. Salas, and B. Moore III. 2005. Mapping Paddy Rice Agriculture in Southern China Using Multi-Temporal MODIS Images. Remote Sensing of Environment 95 (4): 480-492.

Xiao, X., Q. Zhang, B. Braswell, S. Urbanski, S. Boles, S. Wofsy, B. Moore, III, and D. Ojima. 2004. Modeling Gross Primary Production of Temperate Deciduous Broadleaf Forest Using Satellite Images and Climate Data. Remote Sensing of Environment 91 (2): 256-270.

Yao, Y., Q. Qin, S. Zhao, and W. Yuan. 2011. Retrieval of Soil Moisture Based on MODIS Shortwave Infrared Spectral Feature. Journal of Infrared and Millimeter Waves 30 (1): 61-67.

Yilmaz, M. T., E. R. Hunt Jr., and T. J. Jackson. 2008. Remote Sensing of Vegetation Water Content from Equivalent Water Thickness Using Satellite Imagery. Remote Sensing of Environment 112 (5): 25142522.

Zarco-Tejada, P. J., C. A. Rueda, and S. L. Ustin. 2003. Water Content Estimation in Vegetation with MODIS Reflectance Data and Model Inversion Methods. Remote Sensing of Environment 85 (1): 109124

Zhang, H., H. Chen, S. Shen, G. Zhou, and W. Yu. 2008. Drought Remote Sensing Monitoring Based on the Surface Water Content Index (SWCI) Method. Remote Sensing Technology and Application 23 (6): 624-628 (in Chinese).

Zhang, N., Y. Hong, Q. Qin, and L. Liu. 2013. VSDI: A Visible and Shortwave Infrared Drought Index for Monitoring Soil and Vegetation Moisture Based on Optical Remote Sensing. International Journal of Remote sensing 34 (13): 4585-4609.

Zhang, J., Y. Xu, F. Yao, P. Wang, W. Guo, L. Li and L. Yang. 2010. Advances in Estimation Methods of Vegetation Water Content Based on Optical Remote Sensing Techniques. Science ChinaTechnological Sciences 53 (5): 1159-1167.

Zhao, S., Q. Qin, L. You, Y. Yao, N. Yang, and J. Li. 2009. Application of Two Shortwave Infrared Water Stress Indices to Drought Monitoring Over Northwestern China. Geoscience and Remote Sensing Symposium (IGARSS 2009), III-530 - III-533.

Open Access This article is distributed under the terms of the Creative Commons Attribution License which permits any use, distribution, and reproduction in any medium, provided the original author(s) and source are credited. 